\title{
Portrayal of Teachers in Popular Media: Pushing the Frontier of Collaboration with Media Business in Pedagogy and Technology
}

\author{
Orest Cap, Joanna Black \\ Department of Curriculum, Teaching and Learning, Faculty of Education, University of Manitoba, Winnipeg, \\ Manitoba, Canada \\ Email: Orest_cap@umanitoba.ca, blackj@cc.umanitoba.ca
}

Received May 2014

\begin{abstract}
This presentation is based on a unique Summer Institute at the University of Manitoba, Canada in which the presenters examined the relationship between pedagogy and the popular mass media from ([6] Butler, 2000; [12] Maruri, 2012) and beyond [11] Dalton (2010). The image of the teacher provides thematic explorations of school culture, pedagogy, human rights, equality, race, gender, bullying, poverty, stereotyping, and power relations [7] Bulman (2005). The authors of the paper describe a case study which was carried out in a Post Baccalaureate Diploma in Education and Master of Education program at the Faculty of Education over a two-week period in August of 2013 with 24 pre-service public school teachers and technical college instructors.
\end{abstract}

\section{Keywords}

Teachers, Business and Industry Collaboration, Popular Media, Quality Teaching, Partnerships with Business, Image of the Teacher in Films, Faculty of Education and Linkage with Media, University-Industry Cooperation

\section{Introduction}

As far back as September 2009 the President and Vice-Chancellor of the University of Manitoba, David T. Barnard, indicated in the preface to the [1] University of Manitoba Strategic Planning Framework 2009-2014 document that the "University of Manitoba's commitment to teaching and to basic and applied research, in both traditional and professional programs, remains strong. What we are proposing is that we also take advantage of the opportunities that have been identified for us to focus specific attention on areas of particular relevance in today's world. The framework can be seen as a way of forging new connections ... [and] of encouraging collaborations...”. But according to the [2] Organization for Economic Co-operation and Development (OECD) (September, 2012) report entitled Fostering Quality Teaching in Higher Education: Policies and Practices... "fostering quality teaching presents higher education institutions with a range of challenges at a time when the higher education sector is coming under pressure from many different directions... Developing institutions as effec- 
tive learning communities where excellent pedagogical practices are developed and shared also requires leadership, collaboration and ways to address tensions between innovators and those reluctant to change” (p. 3). They further stress that with our institutions' diminishing resources and increased national and international competition, to survive and remain relevant need not only mean that we need to explore alternative pedagogies but we must also strategically co-operate with external stakeholders. Consequently, a closer connection with business and industries could provide authentic opportunities to acquire both generic and professional competencies. In a similar vein the authors of the [3] Business/Higher Education Round Table (B-HERT) position paper No. 7 prepared for the Business/Higher Education Round table of Australia (January, 2002) state in their conclusion that “... business and universities need to work actively to expand the current forms of partnerships and engagement. This should lead to a higher level of interaction and seamlessness between business and higher education”. However, according to [4] Houston (1986) as cited in [5] Boyer (1985) a caveat is in order. He feels that universities have a unique mission and as result “... universities and corporations should built connections, but they must also protect their independence”.

Currently with the new admission standards in place for after degree teacher education programs at the University of Manitoba, many of the teacher candidates are more mature, bring with them expertise in various subject matter, beliefs, values and life experiences. As a result one would need to ask oneself if we as teacher educators should utilize film pedagogy to strengthen teacher education by deconstructing and reflecting on film curricula and take advantage of the prior knowledge of these neophyte candidates. [6] Butler (2000) stated that “... film pedagogy can also create spaces for helping pre-service teachers develop a critical consciousness with regards to education" [and] “... helping them affect change in their classrooms”. The exploration of the image of the teacher via films could provide another source and avenue for the thematic study of school culture, pedagogy, human rights, equality, race, gender, bullying, poverty, stereotyping, and power relations [7] Bulman (2005). The portrayal of teachers on the silver screen provokes a strong reaction [8] Edutopia (2012) from viewers and, for better or worse, creates an influence on the public's perception of the profession [9] Swetnam (1992). Teachers according to [10] Crume (1988) as cited in [6] Butler (2000) can be portrayed in a number of ways: positive (i.e. professional, idealist, friend, self-sacrificing hero), neutral (i.e. coach, love object) and negative (i.e. villain, adversary, buffoon, sex crazed, victim, mad scientist). [11] Dalton (2010) on the other hand refers to teachers as outsiders (i.e. renegade, temporary gig ...), personally involved with students (relationships, savior...), teachers learning from students and the relationships between teachers and administrators. As such, the portrayal of teachers in popular media and the need to examine the relationship between pedagogy and the popular mass media from Hollywood ([6] Butler, 2000; [12] Maruri, 2012) and beyond ([11] Dalton 2010; [13] Dalton, 1995) should be included in a teacher education course. Our response to the stereotypical portrayals was to take on the task of designing a unique Summer Institute course on the "Portrayal of Teachers in Popular Media” which was then held at the Faculty of Education, University of Manitoba, Canada.

In this paper the authors describe a case study [14] Spirer (1980) which was carried out in a Post Baccalaureate Diploma in Education and Master of Education program at the Faculty of Education, University of Manitoba over a two-week period in August of 2013. Through exposure to two new, innovative courses entitled, "Portrayal of Teachers in Popular Media: theory, analysis and pedagogy" and "Portrayal of Teachers in Popular Media: production, art and technology," the authors of this qualitative study report on how participants had an opportunity to explore the theory behind the rhetoric, and be better equipped to recognize how film works to communicate and inspire. The writers further briefly examine how a university faculty of education successfully merged pedagogical and technical digital video expertise with the cooperation of a major media (refer to Figure 1) conglomerate. Sample criteria for a designated assignment is shared with the reader.

\section{Background and Brief Overview of University-Industry Cooperation}

One could trace back to 1906 one of the first university-industry collaboration scheme at the University of Cincinnati, in Ohio. Dean Herman Schneider set up a cooperative education program for the school of engineering for he felt that “... its engineers could be better educated if they spent part of their school career in employment related to their school training and if, in turn, the school program could be related to things the student has learned on the job” [15] Cap (1975). This concept over the years gained in popularity and now can be found even at the secondary and post secondary levels not just in the USA but across Canada. A number of additional suggestions which can be adapted for increasing business, industry and labor cooperation can be found in [16] (Dieffendefer et al., 1977). 


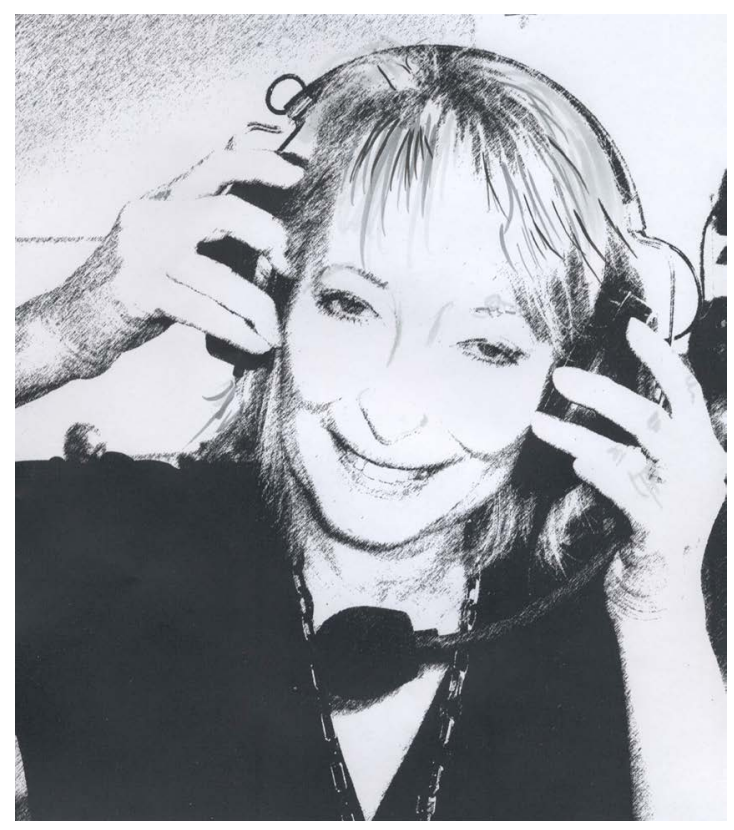

Figure 1. Pre-service teacher listening to the production created in conjunction with Shaw Cable.

Due to the rise of the more knowledge dependent economy the need for strategic partnerships [17] (Edmondson et al., 2012) that go beyond the traditional research projects funding intensify this challenge. Currently University-Business Cooperation (UBC) is undergoing a dramatic flux in relationships as indicated in a recent [18] (Ranga et al., 2013) final report prepared by the London School of Economics Enterprise which reviewed ten US and five case studies from Canada. The [19] European Commission (2009) similarly identified and reviewed thirty countries with good practice as examples in a number of areas of UBC. The [17] Science I Business Innovation Board AISBL reviewed fourteen cases of UBC from US and Europe including a section entitled "Partnerships that impact teaching and learning". Their research suggests four concrete lessons for bridging the industry-university divide: 1) keep the "ship" steady; 2) provide universities the autonomy to operate effectively, and to establish partner ships; 3) encourage and reward via funding incentives strong partnerships and 4) assist universities to strive for excellence. In all three studies it was found that on the basis of the closely illustrated cases a broad diversity of fine examples exist in University Business Cooperation (UBC) and each call for greater partnership expansion and involvement and interaction between the workplace and higher education.

\section{University-Business Cooperation and the Faculty of Education}

Prior to teaching this innovative course, the authors had been involved extensively with a previously successful university-business cooperation project with the Imperial Oil Foundation-Canada entitled "The Imperial Oil Academy (IOA) for the Teaching of Mathematics, Science and Technology from April 3, 2007 to September 30, 2014. This initiative included an IOA Director and 10 other faculty members specializing in the areas of mathematics education, science education and technology education. The mandate was to encourage and support projects which establish, develop, and disseminate improvements in the ways that students of Manitoba learn mathematics, science, and technology. This intensive project helped provide us with essential skills for working with external partners in industry and enhance science, mathematics and technology in the province. Today a number of other universities and organizations have also approached the Imperial Oil Foundation as a potential partner in education. Some of these are: The University of Calgary's Faculty of Education in 2012 for the learning and teaching of science, technology, engineering and mathematics in early school years-Mount Royal University Iniskim Centre in 2011 to help launch an Aboriginal Science and Technology Program-University of Victoria in 2003 to help establish a Centre in Science Education-Queen's University in 2009 to establish a Community Outreach Centre for innovative programs and projects related to literacy, mathematics, science and technology-Scouts Canada in 2013 to establish a science and technology focus for its activities, programs and 
training materials, and York University to help establish annual engineering and science Olympics for high schools students [20] Imperial Oil Foundation (2014).

\section{The Summer Institute}

The two new University of Manitoba, Faculty of Education Post Baccalaureate Diploma in Education and Master of Education graduate courses were scheduled over a two-week period in August of 2013 with 24 pre-service public school teachers and technical college instructors majoring in Adult Education. The two innovative courses were designed and delivered by Dr. Orest Cap, Dr. Joanna Black and Dr. Denis Hlynka. One half of the course was delivered at the Faculty of Education and the other half at the new facilities of the University of Manitoba, School of Art. The six-credit summer institute focused on exploring the theory behind the rhetoric: to enable students to be better equipped to recognize how film works to communicate and inspire. An independent film producer within the filmmaking industry was invited via Skype to provide more in-depth information on the subject of filmmaking. In order to prepare students well, Shaw Communications gave on separate days an one hour in-class presentation focusing on the following topics: day I-dynamics of running a panel, duties of a moderator, addressing the audience and keeping to time within the television production process as well as tailoring the content to fit the television format; day II-importance and use of the rundown sheets and how these help organize the production, mobile television crew examples in action, and the role of Community Access programming. In addition, two of the instructors explored images of teachers throughout history (screening of selected films, episodes of radio and television programs, symphonies-film scoring, folk and popular lyrics, discussion of the Hollywood curriculum and theory). One instructor focused exclusively on writing and examining television content preparation including pre-production and production techniques, studio arrangements and tasks, lighting, directing, communication and switching techniques, camera shots, angles including camera movement (refer to illustrations). In a culminating activity, all students with assistance of television producers, and full broadcasting crew of a major media conglomerate-Shaw Communications Inc. Winnipeg had the opportunity over three full days to take on every role related to digital television production (refer to Figure 2). Finally, the participants produced several specific short digital videos for live distribution to a wide Canadian audience via cable television. To facilitate students' work, sample Institute assignments included specific guidelines, analysis frameworks and rubrics.

The three instructors required participants to firstly produce individual blogs-which tracked their progress over the first week. The task was for each student to maintain five entries, approximately 500 words per blog entry. The blogs contained two parts. Part one provided an opportunity to interact with any course content presented during that day while part two was to create a set of field notes for each film, television program or

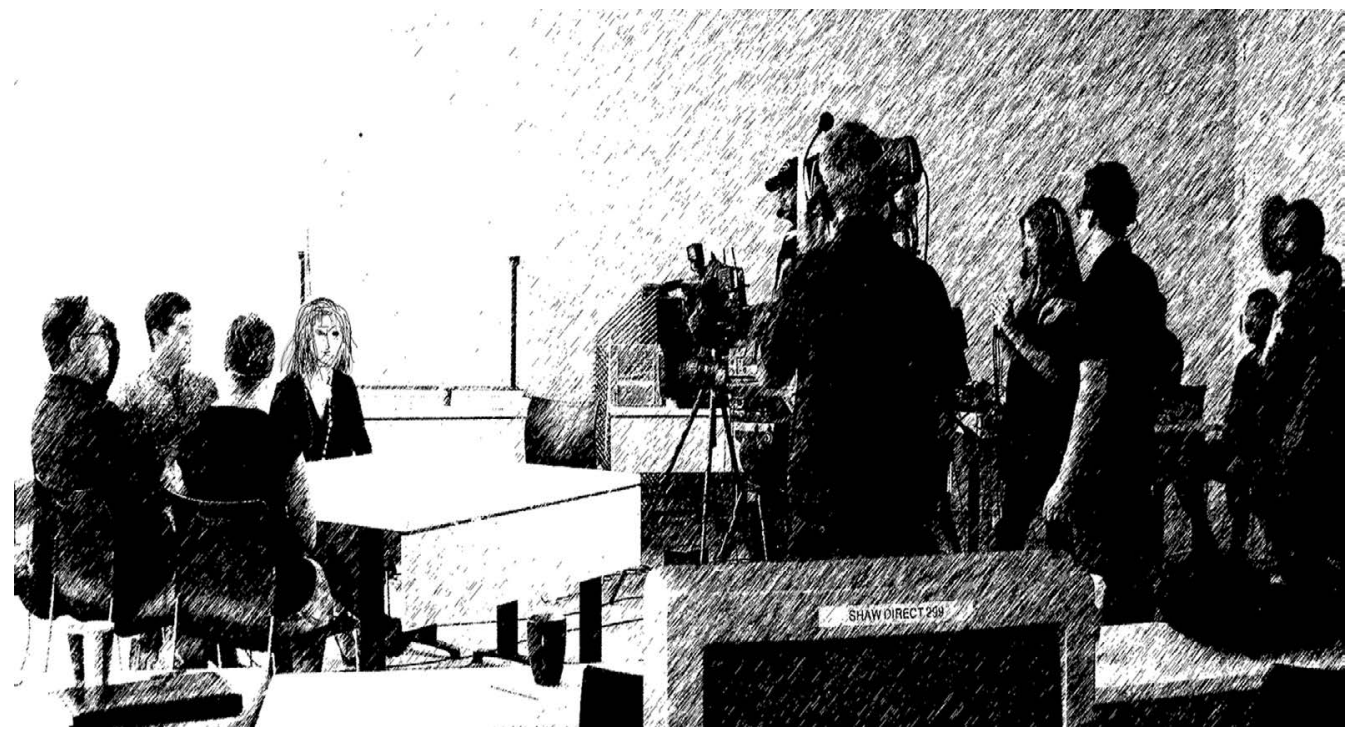

Figure 2. Pre-service teachers during production with interviewees situated to the left and production crew to the right. 
excerpt shown in class. Secondly, School Culture-participants were to select and present in class a DVD film from a given list, secure and view the film. They compared the selected clips of Hollywood school portrayal with realities of their experiences. They also were asked to consider culture, beliefs, values, instructional practices, traditions, behavior rules, demographics of the school and its community. Lastly, students produced (planned, wrote, acted and were behind the camera in production process involved in pre-Production, production and postproduction and their task was to examine media portrayals of teachers. Each of the designated groups created a five minute debate/discussion entitled "Conversations about Media Portrayal of Teachers" based on selected film clips. They were asked to share their own particular viewpoints about being a teacher in comparison to portrayals of teachers by film/television companies. The intent was to prepare content and be involved in a dynamic scenario dealing with a topical curriculum issue in order to demystify the media for the general Winnipeg public and to provide teachers with a voice they would be able to share with the community at large.

Each group had to aid other groups in class with their productions to make this assignment a truly "class community venture". Sample mark breakdown and description for the production assignment follows:

\section{Assignment 3 Debate/Discussion (Live to Tape)}

25\% pre-production (Preparation of the television production); 25\% production (Shoot "live to tape" at Shaw Cable on August 28, 29); 50\% postproduction (Final product and screening—students must be present August 30th)

The television production will be comprised of six groups in the class of approximately four people who will create a debate/discussion entitled, "Conversations about Media Portrayal of Teachers". Students will be involved in the pre-production, production (refer to Figure 3) and postproduction television processes examining media portrayals of educators. The intent is to write content and be involved in a dynamic scenario dealing with a topical curriculum issue in order to demystify the media for the general Winnipeg public. Each group will aid other groups in the class with their productions to make this assignment a truly "class community venture". Assignment Details: Each group will create an approximately five minute production in which five discussion points will be dealt with per group. An audience (comprised of members from our class) may have the option to participate at the end of each production in an approximately two minute discussion. The production involves 1 host who drives the discussion and, 3 to 4 members who address the issues through discussion/debate tactics in front of a live audience which will be filmed to tape. Make certain that a key educational theory/issue discussed in this class and/or the other class will be connected to the television production's theme and issues. The production processes involve: 1) writing the content of the discussion/debate, 2) planning out the session, 3) planning out one or two pertinent professional film/TV segments (of approximately 5 - 30 seconds) to be aired during your live filming and referred to when in production; 4) reenacting the scenario and possibly acting in an audience; 4) learning about and being involved with television production (behind the scenes as Camera Person, Floor Director, etc.) and thus, being involved helping others in the class to bring their work to finished live television format; and finally 5) participating in the analysis-post production process.

\section{Summary}

The Summer Institute is an example of effective collaboration between a community television company and pre-service teachers at the University of Manitoba. Merging business with education is not new to the instructors who have worked with such industries as Imperial Oil and Rogers Cable in the past. Student feedback indicated that the learning was beneficial and valuable for they were trained using professional equipment by people working within the field who shared their expertise with them. Thus, theory and professional practice merged in ways not possible in the traditional classroom. Educators actively sought the collaboration with the industry sector enabling pre-service teachers to learn about professional television production, learn about media images of teachers while at the same time voice their own personal views about these media images based on experiences they have had in their own classrooms. Importantly, as a result of this opportunity it has provided teachers with a voice that, through the television media, reached out to an audience on a community/provincial level. In sum, the writers of this article found that the Summer Institute model enriches and enhances the learning experiences of students, and provides training for teachers so that in the future they can bring this knowledge and skill into their own classrooms. In fact, during the last few months this has indeed occurred. Shaw has been 


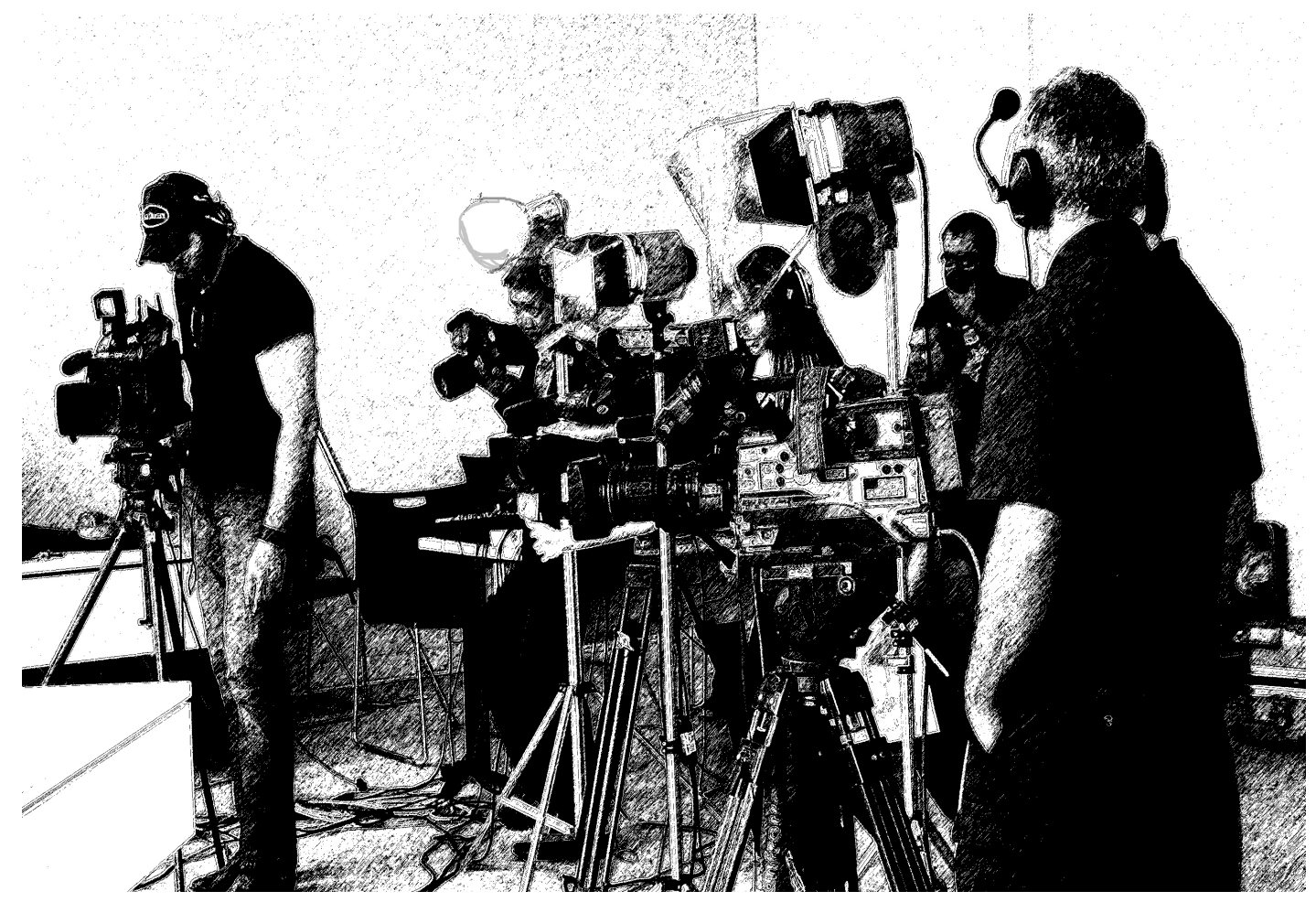

Figure 3. Students learning about the television equipment Shaw Cable provided for the television shoot.

working with two of the teachers at the Summer Institute and their own students in the middle and senior years within the school system. This case study is another tangible example of how to foster "quality teaching" in higher education [2] Henard and Roseveare (2012) and, in addition, how a university faculty of education successfully merged pedagogical and technical expertise with media industry.

\section{References}

[1] Boyer, E.L. (1985) Foreword in N.P. Eurich, Corporate Classrooms: The Learning Business. The Carnegie Foundation for the Advancement of Teaching, Princeton.

[2] Butler, F.J. (2000) Hollywood Films, Reflective Practice, and Social Change in Teacher Education: A Bahamian Illustration. Doctoral Dissertation, Dissertation Abstracts International, McGill University. http://digitool.Library.McGill.CA:80/R-?func=dbin-jump-full\&object id=36880\&silo library+GENO1

[3] Bulman, R.C. (2005) Hollywood Goes to High School: Cinema, Schools and American Culture. Worth Publishers, New York.

[4] Cap, O. (1975) Co-Operative Education Another Avenue to Learning. Education Canada, 25-28.

[5] Crume, M.A.T. (1988) Images of Teachers in Novels and Films for the Adolescent, 1980-1987. Doctoral Dissertation, Dissertation Abstracts International 50, University of Florida.

[6] Dalton, M.M. (1995) The Hollywood Curriculum: Who Is the Good Teacher? Curriculum Studies, 3, 23-44.

[7] Dalton, M.M. (2010) The Hollywood Curriculum: Teachers in the Movies. 2nd Edition, Peter Lang, New York.

[8] Davey, T. and Baaken, T., Muros, G.V. and Meerman, A. (2011) The State of European University-Business Cooperation. Science-to-Business Marketing Research Centre in Munster, Germany.

http://ec.europa.eu/education/tools/docs/uni-business-cooperation_en.pdf

[9] Dieffendefer, R., Kopp, L. and Cap, O. (1977) Business-Industry-Labor Linkages: A Handbook for Improving Personnel Development Programs. The Center for Vocational Education, The Ohio State University, Columbus, ED150434ED150440.

[10] Edutopia (2012) Five-Minute Film Festival: Hollywood Teachers. http://www.edutopia.org/blog/film-festival-hollywood-teacher-movies

[11] Edmondson, G., Valigra, L., Kenward, M., Hudson, L.R. and Belfield, H. (2012) Making Industry-University Partner- 
ships Work: Lessons from Successful Collaborations. Science I Business Innovation Board AISBL.

[12] Fisher, J., Belcher, R., Cairney, T., English, B. and Harding, S. (2002) Greater Involvement and Interaction between Industry and Higher Education. B-HERT Position Paper No. 7, Melbourne. http://www.bhert.com/publications/position-papers/B-HERTPositionPaper07.pdf

[13] Henard, F. and Roseveare, D. (2012) Fostering Quality Teaching in Higher Education: Policies and Practices. OECD Publishing.

[14] Houston, R.W. (1986) Mirrors of Excellence: Reflections for Teacher Education from Training Programs in Ten Corporations and Agencies. Association of Teacher Educators, Reston.

[15] Imperial Oil Foundation (2014) A Partner in the Community, Calgary. www.imperialoil.ca

[16] Maruri, K. (2012) Hollywood Portrayals of Teachers: The Role of Cognitive Dissonance in Critical Pedagogy. Master Thesis Submitted to Gonzaga University, Spokane.

[17] Ranga, M., Hoareau, C., Durazzi, N., Etzkowitz, H., Marcucci, P. and Usher, A. (2013) Study on University-Business Cooperation in the US. Final Report, LSE Enterprise Limited, London School of Economics and Political Science, London.

[18] Spirer, J.E. (1980) The Case Study Method: Guidelines, Practices, and Applications for Vocational Education. The Center for Research in Vocational Education, The Ohio State University, Columbus.

[19] Swetnam, L.A. (1992) Media Distortion of the Teacher Image. JSTR, 66, 30-32. http://www.jstor.org/stable/30188962

[20] Talaba, D. and ten Thij, H. (2007) Teaching and Research Synergy in the Context of University-Industry Cooperation. ZkP-Chevalier de Seyn Publishers, Eindhoven.

[21] University of Manitoba (2009) University of Manitoba Strategic Planning Framework 2009-2014 Report. University of Manitoba, Winnipeg. 